\title{
A Numerical Simulation of a Ni-based Bulk Metallic Glass During Compressive Deformation and Fracture
}

\author{
Liang Weizhong ${ }^{a *}$, Ning Zhiliang ${ }^{b}$, Liu Ailian $^{a}$, An Yongliang ${ }^{a}$ \\ ${ }^{a}$ Heilongjiang University of Science and Technology, Harbin, 150022, China \\ ${ }^{b}$ Harbin Institute of Technology, Harbin 150001, China
}

Received: August 30, 2014; Revised: December 1, 2014

\begin{abstract}
On the basis of compression tests, uni-axial compression deformation and fracture behaviors of NiTiZrAlCuSi bulk metallic glass samples with different dimensions have been studied by numerical simulation approaches. Finite element models for compression simulation have been developed using ABAQUS software. Shear damage models were employed to reproduce the compression deformation and fracture process of the Ni-based amorphous alloys. Mises stress distribution and equivalent plastic strain obtained numerically during compression were analyzed. The simulation results were consistent with those of the compression experiment tests. The smaller of the samples exhibited larger plasticity and higher fracture strength when compared with the bigger one.
\end{abstract}

Keywords: bulk metallic glass, deformation, fracture, numerical simulation

\section{Introduction}

Bulk metallic glasses (BMGs) have shown excellent mechanical properties,including high strength, large elastic strain limit, which makes them ideal for structural and functional applications ${ }^{1-3}$. However, their poor ductility at room temperature has significantly limited their application as a potential engineering material ${ }^{4-6}$. In order to improve the plasticity of the BMGs, the mechanisms of deformation and fracture have been deeply investigated via both experimental and theoretical approaches. The mechanisms of deformation, damage and failure of amorphous solids can be effectively studied by the Numerical simulation method ${ }^{7,8}$. Brest et al. ${ }^{7}$ explored plasticity mechanisms in Zr-based BMGs by means of the diametral compression test and numerical simulation. Distribution of stress and state of equivalent strain in Zr-based BMGs during the compression process were presented. Go et al. ${ }^{9}$ analyzed the stress distribution of laminated $\mathrm{BMG} /$ metal composites via computer simulation using the ABACUS program during a uni-axial fracture. Zhang et al. ${ }^{10}$ researched structural anisotropy in $\mathrm{Cu}$-based $\mathrm{BMGs}$ under uni-axial compression by molecular dynamics simulations. Kim et al. ${ }^{11}$ discussed a stress-overshoot phenomenon in a Pd-based BMGs via finite element analysis under uniaxial compression. However, until now, considerably less simulation has been performed for the deformation and fracture in Ni-based BMGs samples with different diameters at room temperature.

In this paper, on the basis of compression tests, the compressive deformation and fracture behaviors of $\mathrm{Ni}_{42} \mathrm{Ti}_{20} \mathrm{Zr}_{21.5} \mathrm{Al}_{8} \mathrm{Cu}_{5} \mathrm{Si}_{3.5}$ BMG specimens with diameters of $1 \mathrm{~mm}$ and $3 \mathrm{~mm}$ were simulated using ABAQUS software. Mises stress distribution, equivalent plasticity strain, and stress-strain curves of the compressed Ni-based BMG rods were analyzed. Compared with the measurements, the

*e-mail: wzliang1966@126.com deformation and fracture behaviors of the Ni-based BMG samples with different dimensions were discussed based on the numerical results.

\section{Experimental and Numerical Procedure}

After the $\mathrm{Ni}_{42} \mathrm{Ti}_{20} \mathrm{Zr}_{21.5} \mathrm{Al}_{8} \mathrm{Cu}_{5} \mathrm{Si}_{3.5}$ (at\%)alloy was arcmelted, the material was prepared in the form of $1 \mathrm{~mm}$ and $3 \mathrm{~mm}$ diameter cylindrical rods, respectively. The $1 \mathrm{~mm}$ diameter and $2 \mathrm{~mm}$ long rods, and $3 \mathrm{~mm}$ diameter and $6 \mathrm{~mm}$ long rods were used for computer simulation and compression tests. The compression fracture surface features were observed by scanning electron microscope(SEM) and are given in Figure 1.

The explicit finite element calculation software, ABAQUS/ Explicit, was employed for the simulation of compression deformation and fracture of the Ni-based BMG samples. The finite element model of an amorphous cylindrical rod with $1 \mathrm{~mm}$ diameter is depicted in Figure 2. The size of mesh in the element model was $0.05 \mathrm{~mm} \times 0.05 \mathrm{~mm}$ and $0.1 \mathrm{~mm} \times 0.1 \mathrm{~mm}$ for the $1 \mathrm{~mm}$ and $3 \mathrm{~mm}$ sample, respectively. Thus, there were 16560 and 49680 meshes in the $1 \mathrm{~mm}$ and $3 \mathrm{~mm}$ model, respectively. The selected element type was an 8-node linear brick, of reduced-integration elements (C3D8R). In the finite element model, the platen was simplified as a rigid body. General contact was defined between the platen and the specimen, and the tangential friction coefficient was assumed to be 0.1 .The boundary condition for the bottom platen was fixed. The displacement load was applied on the top platen along the 3-axis direction with the other degrees of freedom fixed. In the compression test, the amorphous $\mathrm{Ni}_{42} \mathrm{Ti}_{20} \mathrm{Zr}_{21.5} \mathrm{Al}_{8} \mathrm{Cu}_{5} \mathrm{Si}_{3}$ cylindrical rod suffered damage. Therefore, in order to gain a further insight into the evolutionary process of the damage to the Ni-based BMG sample, a shear damage model built in the standard model library of ABAQUS software was used ${ }^{12}$.The Shear damage 


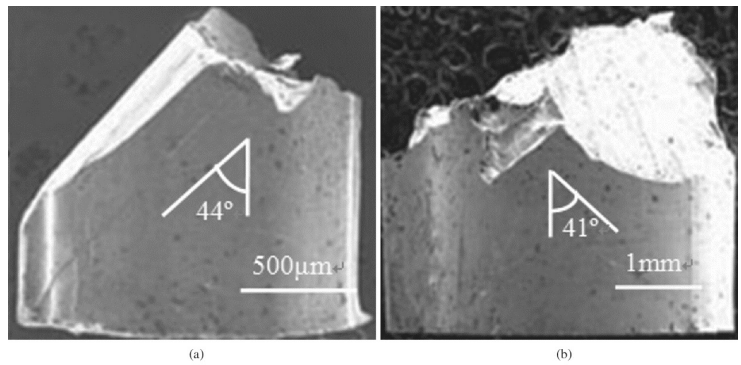

Figure 1. The compressive fracture surface of BMG rods with diameters of $1 \mathrm{~mm}$ (a) and $3 \mathrm{~mm}(\mathrm{~b})$.

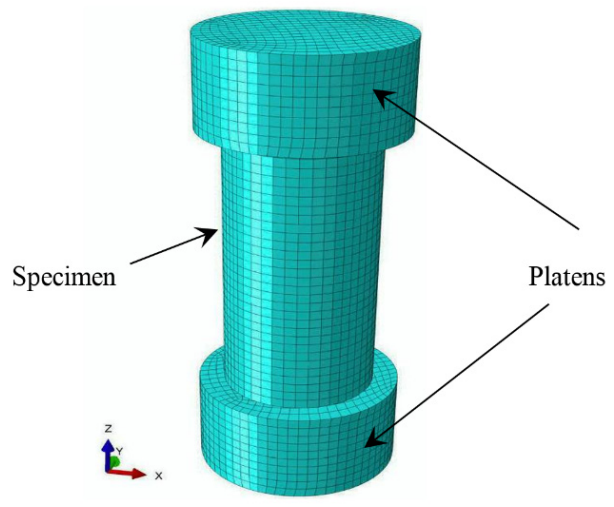

Figure 2. The finite element model of the Ni-based BMG rod with a diameter of $1 \mathrm{~mm}$.

initiation criterion ${ }^{12}$ is a model for predicting the onset of damage due to shear band localization. The model assumes that the equivalent plastic strain at the onset of damage is a function of the shear stress ratio and strain rate. The properties of the present material, elastic modulus(GPa), Poisson ration, density $\left(\mathrm{g} / \mathrm{cm}^{3}\right)$ and fracture strength (MPa) for different Ni-based BMG rods are listed in Table 1.

\section{Results and Discussion}

The computational simulation offers the possibility to observe the stress field. Figure 3 shows the stress distribution of a $1 \mathrm{~mm}$ sample in the compressive deformation and fracture process at different strains. The stress indicator is shown on the right side of each figure in order to indicate the stress upon deformation and fracture. Since the fracture strength of the $1 \mathrm{~mm}$ sample was identified as $4600 \mathrm{MPa}$, the highest stress that $1 \mathrm{~mm}$ sample fractured was indicated at $4600 \mathrm{MPa}$. Mises stress was distributed uniformly on the surface of sample at a compressive strain of $11.62 \%$ (Figure 3a). However, when the compressive strain was $12.25 \%$, shear damage occurred in the middle zone of the sample, resulting in the degradation of material properties and reduction of local stress (Figure 3b). Shear damage evolved along a 45 degree angle from the cylinder axis with a compressive strain of $12.53 \%$, and the Mises stress decreased distinctly (Figure 3c). When the compressive strain was $12.6 \%$, Mises stress decreased dramatically, the fracture happened along a 45 degree angle from the cylinder axis, and the load-carrying capacity of the sample was lowered radically, as shown in Figure 3d.
Table 1. The materials constant used for ABAQUS program.

\begin{tabular}{ccccc}
\hline $\begin{array}{c}\text { Sample } \\
\text { diameters }\end{array}$ & $\begin{array}{c}\text { Young's } \\
\text { modulus } \\
\mathbf{E}(\mathbf{G P a})\end{array}$ & $\begin{array}{c}\text { Possion's } \\
\text { Ration, } \mathbf{V}\end{array}$ & $\begin{array}{c}\text { Density, } \\
\boldsymbol{\rho}\left(\mathbf{g} / \mathbf{c m}^{3}\right)\end{array}$ & $\begin{array}{c}\text { Fracture } \\
\text { stress } \\
\boldsymbol{\sigma}(\mathbf{M P a})\end{array}$ \\
\hline $1 \mathrm{~mm}$ & 68 & 0.39 & 7.8 & 4600 \\
$3 \mathrm{~mm}$ & 76 & 0.38 & 7.65 & 2631 \\
\hline
\end{tabular}

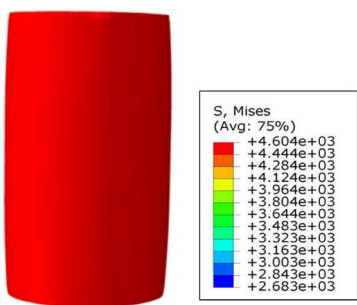

(a)

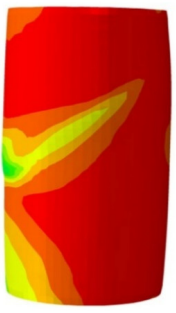

(c)

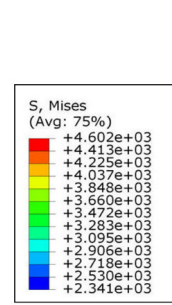

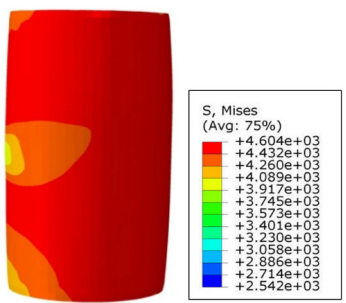

(b)

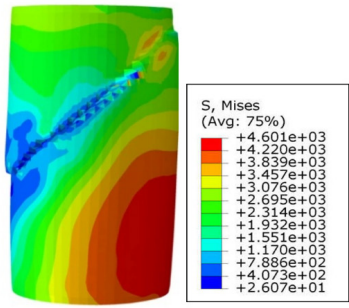

(d)
Figure 3. The stress distribution of $1 \mathrm{~mm}$ sample at different compressive strains, a) $11.62 \%$, b) $12.25 \%$, c) $12.53 \%$ and d) $12.6 \%$.

The equivalent plastic strain maps of the $1 \mathrm{~mm}$ sample in the compressive deformation and fracture process at different strains are given in Figure 4. Material damage took place in the middle region, and the equivalent plastic strain was large in that region at a compressive strain of $11.62 \%$ (Figure 4a). When the compressive strain increased from $12.25 \%$ to $12.53 \%$, the equivalent plastic strain augmented markedly in the direction of $45^{\circ}$ angle to the cylinder axis (Figure $4 \mathrm{~b}, \mathrm{c}$ ). When the strain was $12.6 \%$, the material properties deteriorated sharply, and the element was removed from the mesh due to larger compressive deformation. The fracture happened and the equivalent strain increased drastically in a narrow shear band. It should be noted that the main crack developed along $45^{\circ}$ angle to the cylinder axis (Figure $4 \mathrm{~d}$ ).

Figure 5 shows the stress distribution of the $3 \mathrm{~mm}$ sample in the compressive deformation and fracture process at different strains. Since the fracture strength of $3 \mathrm{~mm}$ sample was identified as $2650 \mathrm{MPa}$, the highest stress that $3 \mathrm{~mm}$ sample fractured at was indicated to be $2650 \mathrm{MPa}$. When the compressive strain increased from $3.81 \%$ to $3.82 \%$, the stresses on the two ends of the sample were large due to stress concentration, and the stress in the middle region was distributed uniformly (Figure 5a-b). However, shear damage occurred in the middle zone of the sample (Figure 5c), and both load bearing capacity and local stress of materials were significantly reduced at a compressive strain of $3.83 \%$.The materials fractured along 45 angle degree to the cylinder axis at a compressive strain of $3.84 \%$, and Mises stress decreased sharply (Figure 5d). 


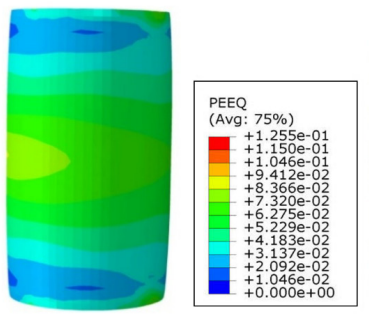

(a)

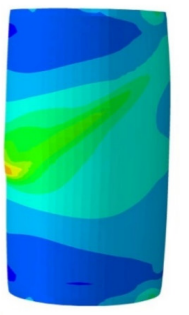

(c)

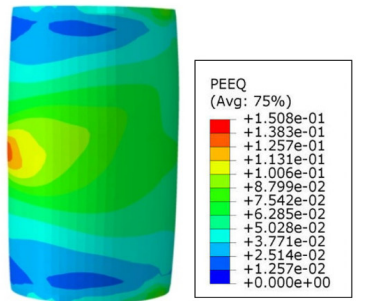

(b)

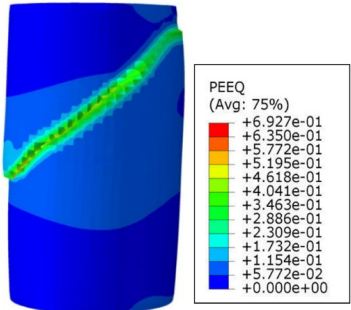

(d)

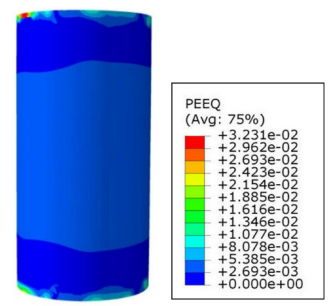

(a)

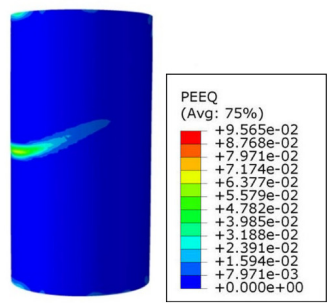

(c)

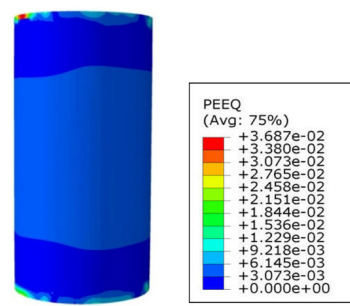

(b)
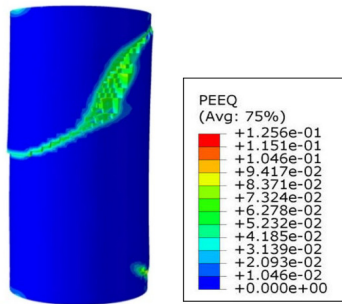

(d)

Figure 4. The equivalent strain maps of $1 \mathrm{~mm}$ sample in the deformation and fracture process at different strains, a) $11.62 \%$, b) $12.25 \%$, c) $12.53 \%$ and d) $12.6 \%$.

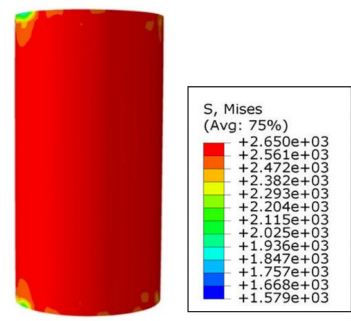

(a)

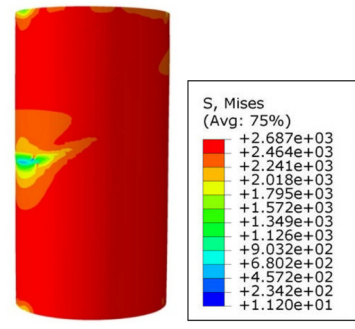

(c)

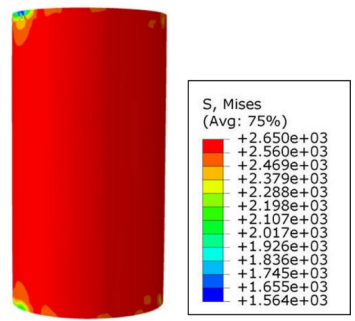

(b)

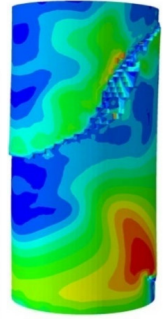

(d)

Figure 5. The Mises stress distribution of $3 \mathrm{~mm}$ sample at different compressive strains, a) $3.81 \%$, b) $3.82 \%$, c) $3.83 \%$ and d) $3.84 \%$.

The equivalent plastic strain maps of $3 \mathrm{~mm}$ sample in the compressive deformation and fracture process at different strains are given in Figure 6. When the compressive strain increased from $3.81 \%$ to $3.82 \%$, plastic deformation occurred on both ends of the sample, and the materials in the middle region displayed linear elastic behavior (Figure 6a-b). However, the equivalent plastic strain increased distinctly along $45^{\circ}$ angle to the cylinder axis at a compressive strain of $3.83 \%$ (Figure $6 \mathrm{c}$ ). When the strain was $3.84 \%$, the material fracture happened in the direction of $45^{\circ}$ angle to the cylinder axis, and the equivalent strain increased drastically in one narrow shear band (Figure 6d).

Figure 6. The equivalent strain map of $3 \mathrm{~mm}$ samples in the deformation and fracture process at different strains, a) $3.81 \%$, b) $3.82 \%$, c) $3.83 \%$ and d) $3.84 \%$.
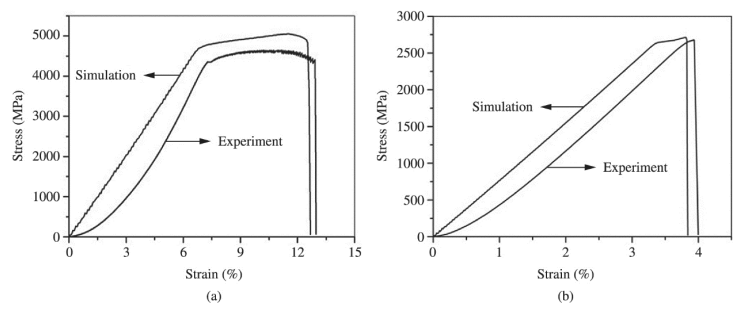

Figure 7. Comparisons between the numerical results and the measurements a) $1 \mathrm{~mm}$ and b) $3 \mathrm{~mm}$.

It can be demonstrated that the equivalent plastic strain of $1 \mathrm{~mm}$ specimen is much larger than that of $3 \mathrm{~mm}$ sample. The equivalent plastic strain of $1 \mathrm{~mm}$ specimen is 0.69 at the moment of fracture, while it's 0.12 for $3 \mathrm{~mm}$ sample. The numerical results corroborate the compressive fracture features (Figure 1). It could be observed that $1 \mathrm{~mm}$ specimen underwent drum-like shaped deformation, while there was no remarkable deformation for $3 \mathrm{~mm}$ sample before fracture. In addition to this, the final compression failure mode of the two samples tended towards shear failure, where the main crack developed along about a $45^{\circ}$ angle to the cylinder axis, in accordance with the experimental results in Figure 1.

The superposition of the experimental and numerical overall stress-strain curves are plotted in Figure 7. The numerical results obtained with shear damage model, corroborated the experimental measurements. It is clear that the compressive responses of the two kinds of specimen were better predicted using a shear damage model.

\section{Conclusion}

1) The Mises stress distributions and the equivalent plastic strains of $1 \mathrm{~mm}$ and $3 \mathrm{~mm}$ samples during compression deformation and fracture were obtained by means of an 
ABAQUS numerical simulation. Much larger deformation was located in one narrow shear band with lower stress. The specimen suffered shear damage along about a $45^{\circ}$ angle to the cylinder axis under a compression load.

2) The failure model of $1 \mathrm{~mm}$ and $3 \mathrm{~mm}$ amorphous alloy samples under compression load was predicted better using the shear damage model, consistent with the experimental testing.

3) The compressive stress-strain curves of $1 \mathrm{~mm}$ and $3 \mathrm{~mm}$ samples were obtained by a numerical simulation approach, in agreement with the experiment measurements. It is clear

\section{References}

1. Song KK, Pauly S, Zhang Y, Sun BA, He J, Ma GZ, et al. Thermal stability and mechanical properties of $\mathrm{Cu}_{46} \mathrm{Zr}_{46} \mathrm{Ag}_{8}$ bulk metallic glass and its composites. Materials Science and Engineering A. 2013; 559:711-718. http://dx.doi.org/10.1016/j. msea.2012.09.013.

2. Kim CP, Oh YS, Lee S and Kim NJ. Realization of high tensile ductility in a bulk metallic glass composite by the utilization of deformation-induced martensitic transformation. Scripta Materialia. 2011; 65(4):304-307. http://dx.doi.org/10.1016/j. scriptamat.2011.04.037.

3. Song KK, Pauly S, Zhang Y, Li R, Gorantla S, Narayanan N, et al. Triple yielding and deformation mechanisms in metastable $\mathrm{Cu}_{475} \mathrm{Zr}_{475} \mathrm{Al}_{5}$ composites. Acta Materialia. 2012; 60(17):60006012. http://dx.doi.org/10.1016/j.actamat.2012.07.015.

4. Wu Y, Wang H, Wu HH, Zhang ZY, Hui XD, Chen GL, et al. Formation of $\mathrm{Cu}-\mathrm{Zr}-\mathrm{Al}$ bulk metallic glass composites with improved tensile properties. Acta Materialia. 2011; 59(8):29282936. http://dx.doi.org/10.1016/j.actamat.2011.01.029.

5. Chen G, Cheng JL and Liu CT. Large-sized Zr-based bulkmetallic-glass composite with enhanced tensile properties. Intermetallics. 2012; 28:25-33. http://dx.doi.org/10.1016/j. intermet.2012.03.054.

6. Gargarella P, Pauly S, Song KK, Hu J, Barekar NS, Samadi Khoshkhoo M, et al. Ti-Cu-Ni shape memory bulk metallic that the plasticity of amorphous alloys is related to the sizes of the samples. The smaller specimen exhibited a larger plasticity when compared with the larger one.

\section{Acknowledgements}

The authors gratefully acknowledge the financial support by the Foundation of Heilongjiang Province Natural Science (A201103), the Foundation of Heilongjiang Province Education (12531585), and the National Natural Science of China (51371078) and (51201062).

glass composites. Acta Materialia. 2013; 61(1):151-162. http:/ dx.doi.org/10.1016/j.actamat.2012.09.042.

7. Brest JS, Keryvin V, Longère $P$ and Yokoyama Y. Insight into plasticity mechanisms in metallic glasses by means of a Brazilian test and numerical simulation. Journal of Alloys and Compounds. 2014; 586:S236-S241. http://dx.doi.org/10.1016/j. jallcom.2013.02.041.

8. Cameron KK and Dauskardt RH. Fatigue damage in metallic glass I: Simulation. Scripta Materialia. 2006; 54(3):349-353. http://dx.doi.org/10.1016/j.scriptamat.2005.10.006.

9. Go YH, Cho J, Jeong CY, Kang CS and Park JS. Stress distribution of bulk metallic glass/metal laminate composites during uniaxial fracture. Materials Science and Engineering A. 2007; 460-461:377-382. http://dx.doi.org/10.1016/j.msea.2007.01.079.

10. Zhang Y, Mattern N and Eckert J. Study of structural anisotropy in $\mathrm{Cu}_{50} \mathrm{Zr}_{45} \mathrm{Al}_{5}$ metallic glass under uniaxial compression by molecular dynamics simulations. Intermetallics. 2012; 30:154157. http://dx.doi.org/10.1016/j.intermet.2012.03.012.

11. Kim HS, Kato H, Inoue A and Chen HS. Finite element analysis of compressive deformation of bulk metallic glasses. Acta Materialia. 2004; 52(13):3813-3823. http://dx.doi.org/10.1016/j. actamat.2004.04.031.

12. ABAQUS. ABAQUS Version 6.10, Dessault systems. Providence; 2010. 